\title{
A new thermally activated battery cell-based forest fire detection and monitoring system
}

\author{
B. Neubauer ${ }^{1}$, J. Sidén ${ }^{2}$, C. Olofsson ${ }^{1}$, M. Gulliksson ${ }^{1}$, \\ A. Koptyug ${ }^{2}$, H.-E. Nilsson ${ }^{2} \&$ M. Norgren ${ }^{2}$ \\ ${ }^{1}$ Sensible Solutions Sweden AB, Sweden \\ ${ }^{2}$ Mid Sweden University, Sweden
}

\begin{abstract}
Detection of forest wildfires at early stages can significantly improve the success of fire fighting and thus it contributes to the damage and cost reduction. Surface deployed sensor networks linked to global nets are often regarded as technically simple options to achieve forest fire detection and progress monitoring. Straightforward solutions with sensor nodes continuously supplying telemetric information demand heavy duty power supplies and periodic service. They are relatively expensive and commonly not environmentally friendly. We have suggested and currently develop an early warning forest fire detection system based on inexpensive, dormant fire-activated detecting sensors and a number of monitoring nodes in a network configuration.

Small deploy-and-forget type sensors contain a radio transmitter with recorded identity number, together with an inactive power element. When activated by high temperature of a developing wildfire, this element produces enough power to support the transmitter, broadcasting the unique identity code until the sensor is completely burnt. Monitoring nodes of such system stand by for sensor activation and forward the alarm information along the monitoring nodes network. Implementation of anti-collision transmission protocols in the sensors allows the monitoring nodes to keep track of fire development and progress.

Monitoring nodes and nodes linking the forest fire detection and monitoring net to public networks can be made using conventional technology and utilizing existing communication networks. Thus significant efforts have been directed to the design of the primary sensors, designing them to be cost efficient and minimizing their environmental impact. Cellulose-based materials are widely
\end{abstract}


used in the sensor construction to decrease its environmental impact and cost. The core of the sensor power element is made of laminated and screen-printed cellulose- based substrates. The power element is activated by a small amount of water, trapped in crystal hydrate salts in storage and released by elevated temperatures of the fire. These salt-based sensors can be manufactured in a rollto-roll manner, making them cost effective. Absence of any liquids or gels in the sensor construction will guarantee a good shelf time.

Keywords: fire activated dormant sensors, forest-deployed sensor network, heat activated dry power element, low environmental impact.

\section{Introduction}

Forest fires can carry serious risks. Strong fires can cause significant deforestation resulting in the loss of wild life and its habitat, seriously changing ground water levels and river flows, changing microclimate etc., private and industrial property damage, but they can also result in the loss of human lives [1, 2]. Because of the population growth and attractiveness of "green living" forests are more and more often exposed to human activities, which can lead to triggering fires along with various natural causes.

Early forest fire detection and precise localisation can significantly reduce problems and costs of fire fighting, simultaneously easing the fire consequences due to higher efficiency of fire tackling $[3,4]$. It is commonly accepted, that forest fire prevention and its detection at earliest possible stages are among the most critical exercises within the proper forest management [5]. Significant progress is currently achieved in all abovementioned areas but fire detection as it is generally more technology dependent as compared to other measures.

Serious efforts today are put into designing early forest fire detection and monitoring systems across the world. Today the area imaging systems using computer analysis of the images taken in different spectral bands by ground, airborn or satellite based cameras, and laser-based (LIDAR type) systems are amongst the most promising solutions suggested [6, 7]). Large area coverage combined with computer processing, allow automated alarm generation and good fire mapping functionality. Unfortunately, such systems require significant amount of power and often call for constant attention of highly qualified technical specialists. In addition, the complexity of managing such systems, rather high deployment and running costs and in some cases inability to respond in real time due to extremely complex data processing, hinder their wide usage. A concise review and comparison of such systems can be found, for example, in the paper by Sidén et al. [8]. More comprehensive survey of the fire detection technologies can be found in the US NISTIR survey [9].

Stationary networks of ground- based sensors with wireless communication can provide an attractive alternative or a valuable addition to the imaging systems for early forest fire detection and monitoring [10-13]. Such systems also have certain advantages compared with imaging systems. For example, wireless communication is not disturbed by heavy smoke produced by the fire. Today it is considered, that the most promising for the wireless fire detection and 
monitoring systems is the concept of "networked" sensor nodes using existing cable or wireless networks [14, 15], or constituting separate dedicated nets $[10-13,16]$. We are taking the networked sensor concept few steps further through the development of inexpensive, environmentally friendly dormant deploy-and forget sensors arranged in star network [8].

\section{Forest-deployed sensor networks}

Technical complexity, serious environmental impact and high deployment and management costs are the worst enemies of the successful solutions for the forest fire detection and monitoring, and sensor network solutions are not exceptional in this respect. Developers of such systems are confronted by multiple, in many cases contradictory demands. A good sensor network system should be able to cover big forest areas, should be easy to deploy, ideally be maintenance-free for several years, have low environmental impact, and the same time should be stable and reliable. The sensors should be relatively small, and should not release dangerous compounds when burnt in the fire.

Traditional node solutions for such networks are active, e.g. contain some actively powered modules $[11,14-16]$. Special measures are often taken to minimize the power demand of such nodes. Also energy scavenging is often used [17-22] to power sensor nodes or helping to refill their drained power sources. So far most of the known active node solutions are battery-supported, which helps to significantly increase the reliability of their operation.

Our analysis has shown that chemical battery and the casing are among the most environmentally unfriendly elements of the modern miniature fire detection network sensors. Today in many countries a special attention is paid to the proper recycling of battery cells due to their negative impact on the environment, see, for example, EU legislations related to battery and accumulator disposal [23] and the documents by the US Environmental Protection Agency [24]. Integrated circuits and passive components present in such sensors have extremely small dimensions, and after decomposition leave very small amounts of ceramics, silicone, gold, silver and carbon together with a small amount of polymers. In the intense fire these elements are usually completely burnt and deeply oxidised, further decreasing their environmental impact. Connecting soldering alloys present in the sensor in very small amount today are becoming more environmentally friendly, and could be substituted by conductive glue to further minimize the environmental impact $[25,26]$. Miniaturisation of the corresponding electronic solutions leads to the significant decrease in the amount of material, used as the circuit board substrate. In general, today all the electronics manufacturers in Europe are encouraged to comply with the RoHS (Restriction of Hazardous Substances) Directive [27], outlining the corresponding European legislations and directives, summarising the relevant definitions and providing examples and explanations. This is not a "zero tolerance" policy, but a reasonable restriction one, aiming at minimisation of the impact of electronics on the environment. 


\section{Dormant sensors in forest fire detection networks}

Previously we have reported on the feasibility of dormant, Action Activated sensor application in the forest fire detection networks [8].

Inexpensive dormant deploy-and-forget sensors in this case are supported by much smaller number of the active, battery-powered active nodes forming a network (Figure 1). During the deployment dormant sensor identity is automatically linked to its position: just before the deployment ID tag of the particular sensor is read and saved in the monitoring computer together with the GPS coordinates of a deployment point. Each of the active base stations $\left(B_{1}-B_{3}\right.$ in Figure 1) is monitoring its own area. When the base station $\mathrm{B}_{1}$ receives the alarm signal from the sensor activated by fire it sends the identities of active sensors through the other base stations $\left(\mathrm{B}_{2} \gg \mathrm{B}_{3} \gg \ldots\right)$ to the station having access to the global network $\left(\mathrm{B}_{4}\right)$ and further- to the monitoring system. By knowing when and which sensors are activated the fire progress can be monitored.

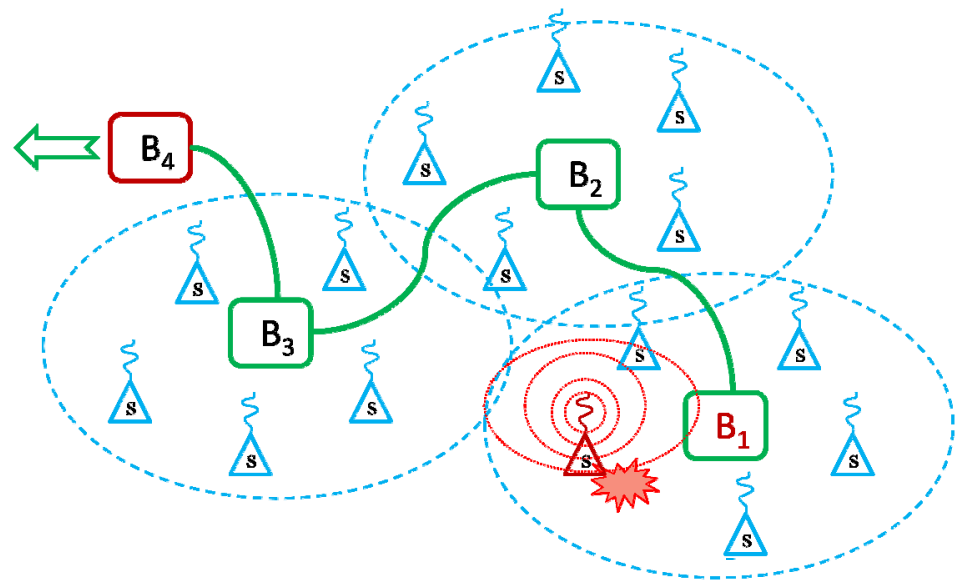

Figure 1: Wireless network with dormant sensors (s) and active stations (B).

Early sensors we have developed and tested (Figure 2) were using dry power elements constructed of the rolled paper strips with the screen-printed material on them (Figure 2b). Such power element is activated by a small amount of water, released from coated paper container plugged with the wax, melting at certain rather high temperature (Figure $2 \mathrm{c}$ ). The casing of the sensor was made from the multi-layered paper. Transmitting antenna was done from a section of the thin copper wire. Field tests of early sensor prototypes in artificial fires have shown that their survival time even in intense fire (40-60s) is adequate for the signal detection and sensor identification by the network nodes. Special research was conducted to study the feasibility of using cellulose-based substrates as the carrier for the electronics component. Figure 2a illustrates one of such options with the conductors made using screen printing of conductive ink. Unfortunately the uneven surface of the untreated cellulose- based substrates does not allow for the consistent levelled surface of the conductive layers, 


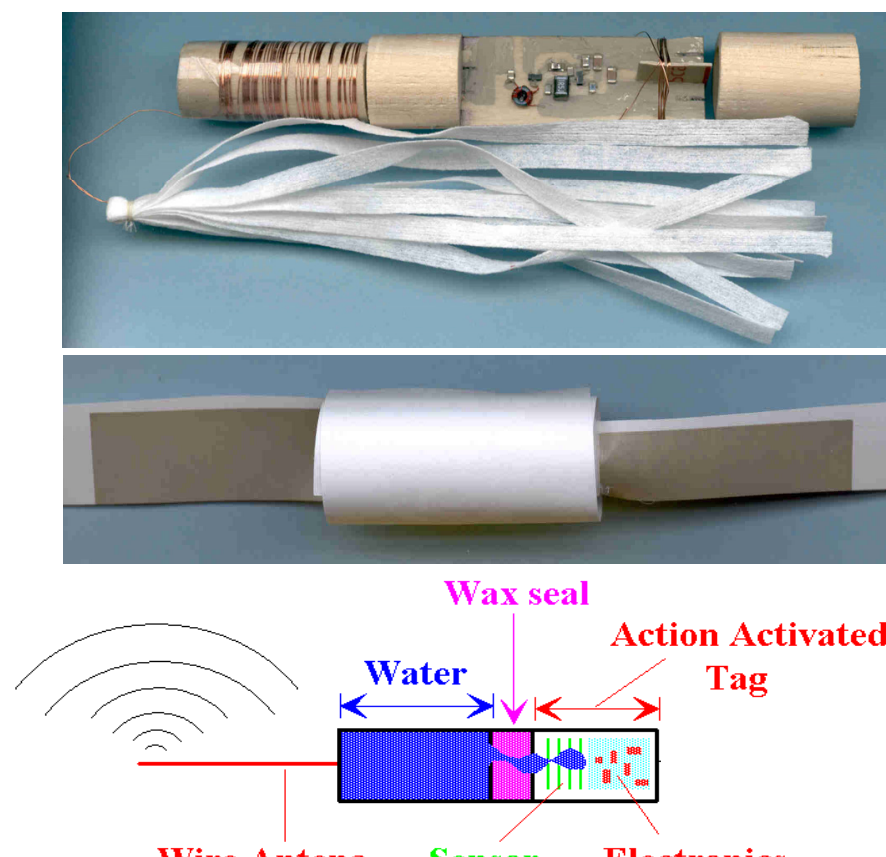

Figure 2: $\quad$ Early model of deploy-and-forget sensor with water-activated dry power element. See text for details.

needed for the successful mounting of small surface-mount electronic components. Also the capillary effects are leading to the uncontrolled spreading of the paint at the edges of the conductor pattern, strongly decreasing the resulting conductor pattern resolution. And in such case it is hardly possible to use miniaturised electronic chips with high degree of integration and increase the size of the substrate, and the amount of conducting ink used. This, in turn, increases the cost of the solution. Treatment of the cellulose-based substrates allowing for accommodation of high resolution conductor patterns for the miniaturised electronic circuitry turns it into something almost equivalent to the modern thin printed board substrates. So to the moment it was concluded, that the miniature electronic circuitry manufactured in traditional RoHS-compliant technologies is a reasonable compromise.

Demands to the sensor casing are also quite contradictory. On one hand, it should be rather environmentally stable, or else the sensor will have a short lifetime when deployed. On the other hand, it should be environmentally friendly. The chosen compromise solution is using multi-layer tube made of waxed paper. Developed paper casing provides good balance between the longevity of the sensor at ambient conditions and the same time lowest possible environmental impact. Figure 3 illustrates the results of the fire tests of the sensor prototypes carried out to determine the transmission time before node destruction. Developed water-activated power element also are much more 

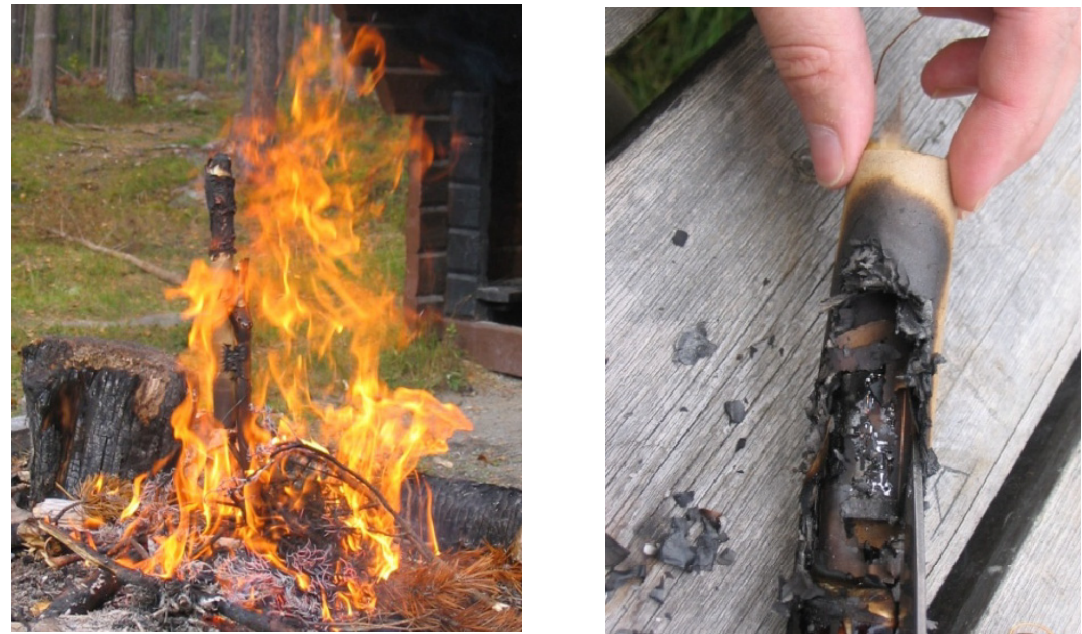

Figure 3: $\quad$ Field fire tests of the deploy-and-forget sensor prototypes.

environmentally friendly than cell batteries, which have much larger amount of chemicals and often explode in the fire spreading the contamination.

But these water-containing sensors have certain drawbacks. Wax materials are amorphous and have a tendency to slowly deform (flow) even at the temperatures below melting point. Thus without thorough studies it is not possible to forecast the longevity of the sensors deployed at ambient conditions or even stored for a long time at room temperature. There is also a possibility of the improper orientation of the sensors, especially when they are deployed automatically. In situations when the sensor is placed with the water container under the sensor, the water will never reach the dry battery cell even when the wax plug is molten by the fire. Presence of the water container in dormant sensors also complicates their manufacturing and drives up their manufacturing cost.

\section{Temperature activated power elements for forest fire detection sensors}

Modern electronic components and construction materials are already adequate for the manufacturing of small, inexpensive electronics for dormant sensors capable of wireless communication with a range of a few kilometres. Early experiments have forced us to conduct further studies seeking for the adequate power element constructions of such sensors, free of the drawbacks discussed above. One of the possible solutions is to use crystal hydrate salts as electrolyte for the dry power cells of the dormant fire sensors.

Thermally activated cells with solid electrolyte are known and are often used in military applications [28, 29], where the functionality and performance are clearly dominating over the potential environmental hazards. In such cells the 
electrolyte needed for obtaining a fully functional battery element is not a solution or gel, but rather a molten salt. Crystal hydrate salts incorporate water molecules within the structure of their solid crystals. This water can be released when the temperature increases over a certain threshold, turning the dry crystals into liquid electrolyte necessary for the functioning of power elements. For example, sodium acetate trihydrate, $\mathrm{CH}_{3} \mathrm{COONa} \cdot 3 \mathrm{H}_{2} \mathrm{O}$, generally a dry solid at room temperature begins to melt at $58^{\circ} \mathrm{C}$. This separates the crystal water from the sodium acetate, $\mathrm{CH}_{3} \mathrm{COONa}$, which in turn starts to dissolve, and at temperatures above $79^{\circ} \mathrm{C}$ all sodium acetate dissolves completely in the released water [30]. Magnesium acetate tetrahydrate, $\left(\mathrm{CH}_{3} \mathrm{COO}\right)_{2} \mathrm{Mg} \cdot 4 \mathrm{H}_{2} \mathrm{O}$ behaves in similar fashion, having slightly higher triggering temperature of $80^{\circ} \mathrm{C}$. Both crystal hydrate salts are much more environmentally friendly as compared to the lithium halides employed in traditional thermally activated batteries [28, 29]. Sodium acetate is defined by the EU authorities as food additive E 262 [31] so its environmental impact is very low.

It should be noted, that printed battery technology is already well developed, and used commercially [32] being quite cost effective. So we have developed corresponding technology for industrial screen-printing and easy assembling of the single- and multi-cell power elements using paper substrates, two of the mentioned crystal hydrate salts as electrolyte and different types of pick-up electrodes, e.g. screen- printed, copper wire, perforated aluminium foil ones.

Figure 4 illustrates the main stages of the single-cell element construction. First, the pick-up carbon electrodes are screen-printed on two paper substrates. After drying, anode and cathode active layers are printed on the opposite sides. The anode layer is printed on the paper substrate with special carbon black and Zn suspension in ethanol [33] is placed on the fixation tape (Figure 4a) with the active layer on the upper side. Separator paper sheet is placed over (Figure 4b). It is covered by a thin layer of the dry crystal hydrate salt and over it by another paper substrate with the cathode layer (Figure 4c). Cathode layer is screenprinted on the paper substrate using the suspension of manganese dioxide $\left(\mathrm{MnO}_{2}\right)$ powder in a water-based carbon ink [34]. The anode layer is facing the
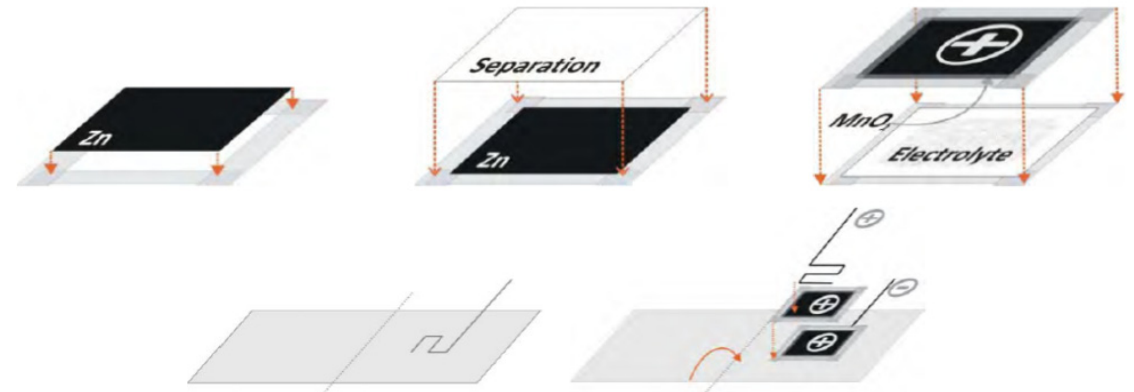

Figure 4: Schematic illustration of the E 262- based fire activated power cell manufacturing process. 
crystal hydrate salt. Thus after assembling both outer sides of the "sandwich" carry the carbon ink electrodes. This stack constitutes a dry single cell power element that can be activated at the elevated temperatures.

In order to make multi-cell dry dormant power elements few of such cells are first stacked together with the cathode of previous cell touching the anode of the next. In order to improve the efficiency of the elements wire- or perforated foil pick-up electrodes are introduced to the outermost carbon electrodes of the multi-cell element (Figure $4 \mathrm{~d}$, e) and the cell is sealed using adhesive tape or paper. It should be noted that major elements of this technology were developed and tested during our work on the moisture sensors [35], carried out earlier.

To thoroughly assess the new power element performance special measurement laboratory setup was designed and constructed. As the designed power elements should effectively support small transmitters working in both continuous and burst modes for the period of time necessary for their detection and identification two test protocols, with continuous and burst power draining were used, mimicking the operation of the sensor with $10 \mathrm{dBm}$ transmitter and small microcontroller. For the activation the sensor elements were wrapped around the copper tube heated up by the hot air flow of a heat gun. In both protocols the activation time of the power elements (the time from the start of heating to the moment when the power element provides enough power to start transmitting) were recorded. Curve irregularities in first $150 \mathrm{~s}$ are caused by the measurement system testing, if the cells are activated and ready to operate.

Experiments have shown that power elements with the chosen acetate crystal hydrate when activated have similar open circuit (unloaded) voltage of about 1.2$1.3 \mathrm{~V}$ per cell. But the elements with sodium acetate trihydrate (E 262) cells have significantly better loaded performance in both the continuous and burst current drain tests for the same size elements, as compared to the magnesium acetate based ones. Multi-cell E 262 based power elements were capable of supporting chosen transmitter operation with alternating current drainage of 40 and $170 \mathrm{~mA}$ for up to 300-400 s. The thermally activated three-cell E 262-based power elements with an electrode surface of $25 \mathrm{~cm}^{2}$ were capable of peak powers up to $0.45 \mathrm{~W}$ with $170 \mathrm{~mA}$ drained current, and have available energy of at least 10 20 Ws. Commercial CR2032 Li-Mn batteries in the same test yield peak powers in the range of $0.38-0.41 \mathrm{~W}$, which is very similar (Figure 5).

Though printed power elements cannot provide the same endurance as commercial button cells, they still show similar performance for about 300-600 s after activation, which is exceeding the expected survival time in the intense fire. They also are capable of providing adequate power for the small transmitters operating in a burst mode. Figure 6 shows the results of the performance test of an E 262-based two-cell power element with $5 \times 5 \mathrm{~cm}^{2}$ working area and perforated foil pick-up electrodes with the load mimicking the burst type transmitter. After about $87 \mathrm{~s}$ of heating the cell is activated and $40 \mathrm{~mA}$ current is drained for $2 \mathrm{~s}$. This mimics the control electronics operation with the transmitter inactive. After that $170 \mathrm{~mA}$ current is drained for 1s (mimicking the period of 


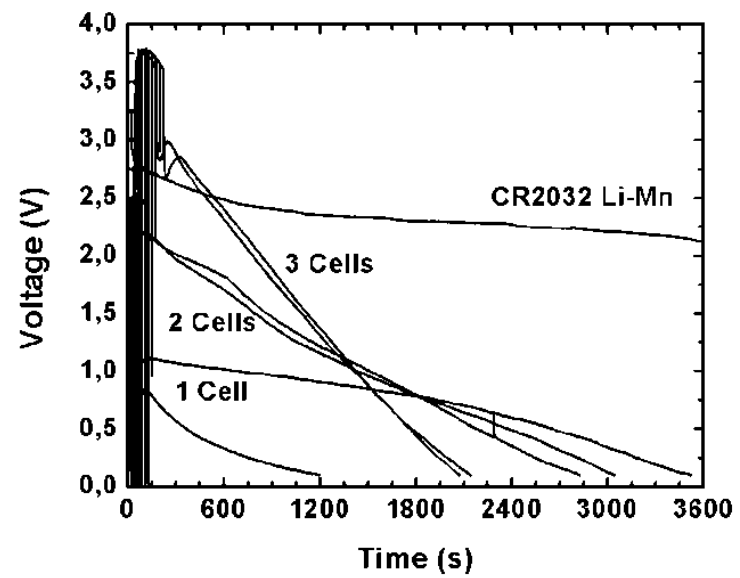

Figure 5: Constant-current discharge curves for one- two- and tree-cell battery sensors with E 262-based electrolyte and working surface area of $25 \mathrm{~cm}^{2}$ as compared to the ones of commercial CR2032 LiMn battery.

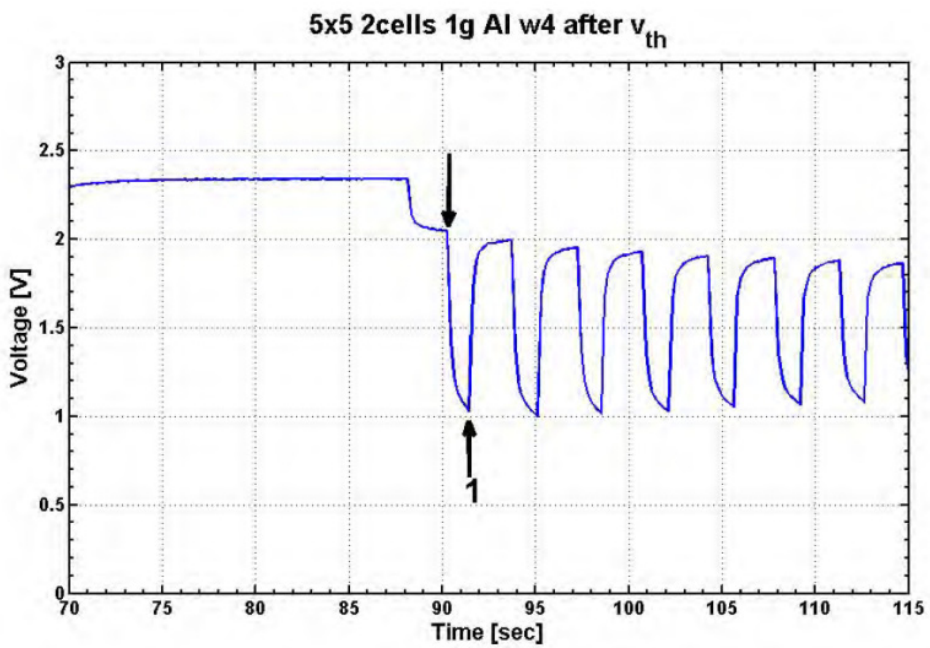

Figure 6: Performance test of an E 262-based two-cell power element with the load mimicking the burst type transmitter. See text for details.

data transmission). The upper arrow shows the start and the lower one- the end of the first $1 \mathrm{~s}$ "transmission" interval. After that both intervals are periodically repeated. Though the output voltage of the element drops under the load during the "transmission" interval, it does not fall below the values necessary for the operation of the chosen electronic circuits. 
Measured activation times for the single- and multi- cell E 262-based power elements were generally higher than expected, ranging from $40-60 \mathrm{~s}$ for the single cell to 100-200 s for the two- and three-cell elements. But these also include the heating time needed to increase the temperature of the copper tube, carrying the power element in the laboratory set up. Additional studies are needed to determine how the activation times of the power elements are affected by placing the sensor elements inside the tube sensor casing described earlier. We know from initial experiments that a well designed paper-based outer casing provides the few critical minutes of sensor survival needed and that the activation times of the sensors are at least not larger than the ones measured in the described experiments. These times are already quite adequate for the alarm generation task.

The dimensions of the power elements can be chosen from the demanded energy determining the active surface area and, partly, the thickness of the crystal hydrate layer. Average thickness of the power element made in the described technology is about was $1.7 \mathrm{~mm}, 3.3 \mathrm{~mm}, 4.5 \mathrm{~mm}$ and $7 \mathrm{~mm}$ for the one-, two-, three and four-cell constructions. Perforated foil electrodes, which appeared to be some more effective than wire ones, add another $0.2-0.3 \mathrm{~mm}$ to the overall thickness of the power element. The volumetric power density provided by the tested printed batteries strongly depends on the current draining conditions. $25 \mathrm{~cm}^{2}$ E 262-based power elements with constant $30 \mathrm{~mA}$ current draining provide $4-6 \mathrm{Ws} / \mathrm{cm}^{3}$ density and with $40 / 170 \mathrm{~mA}$ cycling the power density is $1-3 \mathrm{Ws} / \mathrm{cm}^{3}$.

\section{Conclusions}

Dormant power elements made in commercial screen-printing technology with paper type substrates and based on the crystal hydrate salts, such as sodium acetate trihydrate (E 262) provide a very good alternative to the traditional batteries for powering the deploy-and-forget sensors of the forest fire detection and monitoring wireless networks. Though their endurance and peak power are in many cases still lower than the ones provided by the commercial battery cells, they are quite capable of providing adequate power for the small transmitters and control circuitry of the dormant fire detection sensors. At the same time, such printed power elements are significantly more environmentally friendly as compared to the traditional batteries and to the other thermally activated power cells. Due to their construction printed power elements with crystal hydrate salts have the potential to show significantly longer safe storage times as compared to many of the traditional battery cells. And due to manufacturing technology they are well suited for cost effective bulk production.

\section{References}

[1] Forest Fires in Southern Europe, European Commission Environment and Geo-Information Unit Report, July 2001, http://ec.europa.eu/echo/ civil_protection/civil/pdfdocs/forestfiresreportfinal.pdf 
[2] Henderson, M., Kalabokidis, K., Marmaras, E., Pavlos Konstantinidis, P., and Marangudakis, M., Research in Human Ecology, 12(2), pp. 169-182, 2005.

[3] Martell, D.L., and McAlpine R.S., in: Wildfire Detection Workshop, March 25 - 27, 2003, Hinton Alberta, Canada.

[4] Kułakowski, P., Calle, E., and Marzo, J.L., International Journal of Communication Systems, published online: 1 MAR 2012, DOI: 10.1002/dac.2311.

[5] Concept of Forest Fire Protection in the Russian Federation, International Forest Fire News (IFFN)32, pp. 113-118, January-June 2005, available online: www.fire.uni-freiburg.de/iffn/iffn_32/19-Agency-Concept.pdf

[6] Utkin, A.B., Fernandes, A., Simões, F., Lavrov, A., and Vilar, R., International Journal of Wildland Fire,12(2), pp. 159 - 166, 2003.

[7] Utkin, A.B., Lavrov, A.V., Costa, L., Simões, F., and Vilar, R., Applied Physics B: Lasers and Optics, 74(1), pp. 77-83, 2002, DOI: 10.1007/s003400100772.

[8] Sidén, J., Gulliksson, M., Koptyug, A., Nilsson, H.-E., IFIP International Federation for Information Processing, 248/2007, pp. 47-58, 2007, DOI: 10.1007/978-0-387-74899-3_5.

[9] Cleary, T., and Grosshandler, W., NISTIR 6356, Survey of Fire Detection Technologies and System Evaluation/Certification Methodologies and their Sustainability for Aircraft Cargo Compartments, July 1999, available online: fire.nist.gov/bfrlpubs/fire99/PDF/f99037.pdf

[10] Hefeeda, M., and Bagheri, M., Ad Hoc \& Sensor Wireless Networks, 7(3-4), pp. 169-224, April 2009.

[11] Zhang, J., Li, W., Han, N., and Kan, J., Front. For. China, 3(3), pp. 369374, 2008, DOI: 10.1007/s11461-008-0054-3.

[12] Lloret, J., Garcia, M., Bri, D., and Sendra, S., Sensors, 9, pp. 8722-8747, 2009, DOI:10.3390/s91108722.

[13] Bahrepour, M., Meratnia, N., and Havinga, P.J.M., Technical Report TRCTIT-08-73, Centre for Telematics and Information Technology University of Twente, Enschede, 2008, ISSN 1381-3625.

[14] Dunkels, A., Voigt, T., Alonso, J., Ritter, H., and Schiller, J.,Proc.2d Intl Conf. on Wired/Wireless Internet Communications (WWIC2004), Frankfurt (Oder), Germany, February 2004, Springer-Verlag.

[15] Rodriguez, N., Bistue, G., Hernandez, E., and Egurrol, D., Proceedings of ISTAS 2000, Roma, September 2000, pp. 133-136, 2000.

[16] Kremens, R., Faulring, J., Gallagher, A., Seema, A., and Vodacek, A., International Journal of Wildland Fire, 12(2), pp. 237-244, 2002.

[17] Roundy, S., Wright, P. K, and Rabaey, J. M., "Energy Scavenging for Wireless Sensor Networks: with Special Focus on Vibrations", Kluwer Academic Publishers, 2004.

[18] Yeatman, E.M., in: Proc. 2nd Intl Workshop on Advances in Sensors and Interface, IWASI 2007, pp. 26-27, June 2007.

[19] Mathúna, C.O., O'Donnell, T., Martinez-Catala, R.V., Rohan, J., and O'Flynn B., Talanta, 75(3), pp. 613-623, 2008 May 15; Epub 2007 Dec 26. 
[20] Gilbert, J.M., and Balouchi, F., International Journal of Automation and Computing, 05(4), pp. 334-347, October 2008, DOI: 10.1007/s11633-0080334-2.

[21] Venkataraman, H., Muntean, G.-M., Green Mobile Devices and Networks: Energy Optimization and Scavenging Techniques, CRC Press, 2012.

[22] Paradiso, J.A., and Starner, T., IEEE Pervasive Computing archive, 4(1), pp. 18-27, 2005.

[23] Summary of EU Waste Legislation on Batteries and Accumulators. http://ec.europa.eu/environment/waste/batteries/index.htm

[24] US Environmental Protection Agency, Wastes - Resource Conservation Common Wastes \& Materials. http://www.epa.gov/osw/conserve /materials/battery.htm

[25] Andrae, A.S.G, Itsubo, N., Yamaguchi, H., and Inaba, A., Materials Transactions, 48(8), pp. 2212-2218, 2007.

[26] Yim, M.J., and Paik, K.W., Electronic Materials Letters, 2(3), pp. 183-194, 2006.

[27] RoHS Directive (European Union Directive on the Restriction of Hazardous Substances). http://www.rohs.eu/english/index.html

[28] Guidotti, R. A., and Masset, P., Journal of Power Sources, 161(2), pp. 1443-1449, 1996.

[29] Masset, P, and Guidotti, R. A., Journal of Power Sources, 164(1), pp. 397414, 2007.

[30] Green, W. F., Journal of physical chemistry, 12, pp. 655-650, 1908

[31] Food additive list: http://www.foodlaw.rdg.ac.uk/additive-list.htm or http://en.wikipedia.org/wiki/E_number

[32] Paper Battery Co, http://www.paperbatteryco.com/

[33] XZ302-1 MV 1K Curing Conductive Carbon, Product no. CHSN8033, Sun Chemical Circuits, Norten Hill, Midsomer Norten, Bath BA3 4RT, UK.

[34] 124-39 Carbon Filled, Waterborne, Low V.O.C., Screen-Printable, Conductive Ink \& Coating, Creative Materials, Inc. 141 Middlesex Road T978.649.4700 Tyngsboro, MA 01879.

[35] Nilsson, H.-E., Sidén, J., Unander, T., Olsson, T., Jonsson, P., Koptioug, A., and Gulliksson, M., in Proc. IEEE Polytronic 2005 Conf., pp. 82-85, 2005. 